\title{
ACUTE INTESTINAL OBSTRUCTION- A RARE PRESENTATION OF MUCINOUS CYSTADENOMA OF APPENDIX
}

\author{
Sourabh Mukharjee ${ }^{1}$, Harshit Agarwal2 ${ }^{2}$, Chikila Kanak Durga ${ }^{3}$, Anil Kaler ${ }^{4}$, Rachan Kathpaul ${ }^{5}$
}

\begin{abstract}
HOW TO CITE THIS ARTICLE:
Sourabh Mukharjee, Harshit Agarwal, Chikila Kanak Durga, Anil Kaler, Rachan Kathpaul. "Acute intestinal obstruction-A rare presentation of mucinous cystadenoma of appendix". Journal of Evolution of Medical and Dental Sciences 2015; Vol. 4, Issue 64, August 10; Page: 11240-11243, DOI: 10.14260/jemds/2015/1618
\end{abstract}

\begin{abstract}
Mucocele of appendix (MA) is a rare entity and is defined as mucin filled dilated appendicular lumen which may be due to distal obstruction. It is usually asymptomatic and may present as appendicitis. We present a rare case of an elderly female who presented with features of acute intestinal obstruction secondary to mucinous cystadenoma of appendix for which she had to undergo exploratory laporotomy.
\end{abstract}

KEYWORDS: Mucocele appendix.

INTRODUCTION: MA refers to dilated mucin filled appendicular lumen which may be secondary to distal obstruction. It is a rare condition with estimated incidence of only $0.2-0.3 \%$ in appendicectomy specimens.(1) It can be asymptomatic, but acute or chronic pain in the right iliac fossa is the most frequent symptom.(2) Intestinal obstruction complicating an appendiceal mucocele has rarely been reported.(3) We describe the case of an old woman who came to emergency with signs and symptoms of intestinal obstruction due to appendiceal mucocele.

CASE REPORT: We report the case of a 60years old, previously healthy woman, who presented to our emergency room with a 3day history of acute and diffusely abdominal pain, nausea, vomiting and disruption of bowel movements. Her abdomen was distended and tympanic with diffuse tenderness, especially in the periumbilical areas with exaggerated bowel sounds. She had a history of ant tubercular treatment for pulmonary koch's 5years back. She also had a history of an episode of subacute intestinal obstruction 6 months back which was managed conservatively outside. The leukocyte count was 22,000 with $95 \%$ neutrophils.

An erect film of the abdomen revealed multiple air fluid levels suggestive of small bowel obstruction. CECT abdomen was done which showed small bowel dilatation with abrupt tapering near IC junction with mesentric lymphadenopathy. So, a diagnosis of acute intestinal obstruction secondary to ileocaecal koch's was made. After resuscitation, patient was undertaken for exploratory laporotomy. On inspection, dilated small bowel loops with collapsed large bowel mesentry were found and a $4 * 3 \mathrm{~cm}$ in size firm mass was found at the anatomical site of appendix. The mass was preileal in position and was compressing over terminal ileum. About $10 \mathrm{ml}$ mucinous collection was found in right iliac fossa and pelvis. So, right sided hemicolectomy was performed. The postop period was uneventful and patient was discharged on day 11 in satisfactory condition. The final histopathology showed mucinous cystadenoma of appendix collection and reactive lymphoid hyperplasia with no epithelial cells in mucin. 


\section{CASE REPORT}
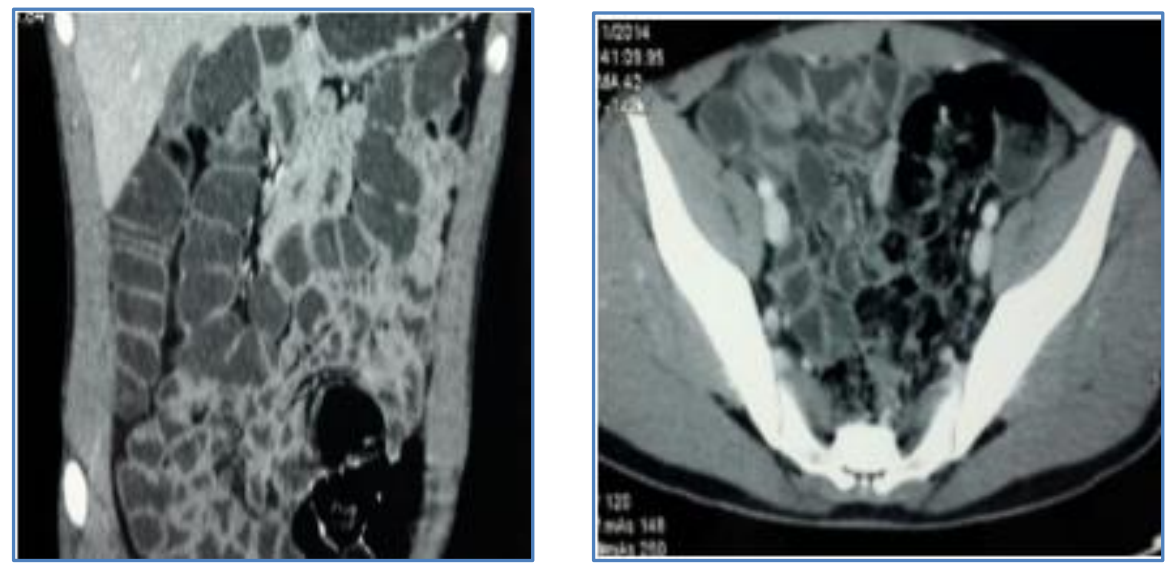

CT scan showing dilated bowel loops with abrupt cut off at terminal lieum
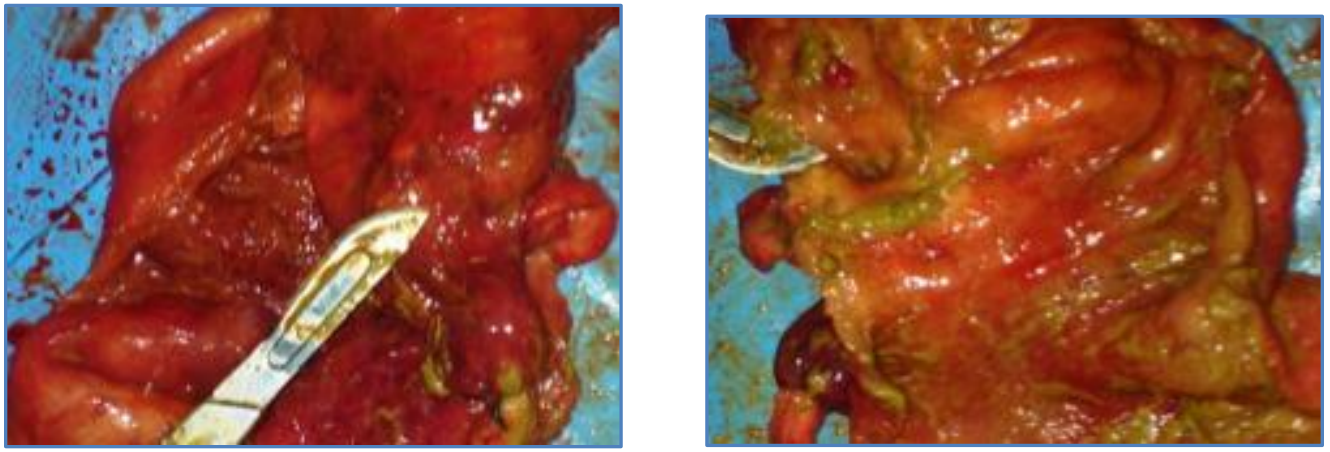

Intraoperative pictures showing mass at ic junction and appendicular lumen lieum

DISCUSSION: Appendiceal mucoceles are a group of diseases characterized by filling of appendiceal lumen by mucin. It consists of 4 histopathological findings: simple mucocele or retention cyst, mucosal hyperplasia, mucinous cystadenoma, and mucinous cystadenocarcinoma. (4) The incidence of MA is relatively rare with mucinous cystadenocarcinoma being the rarest. It is usually and presents as incidental finding in 50\% of patients at the time of surgery.(2) The most common clinical feature is right iliac fossa pain followed by abdominal mass, weight loss, nausea, vomiting.

They may present as acute appendicitis or as an abdominal mass. [5] Other rare presentations include intestinal intussusception,[5] torsion,(6) or ureteral obstruction.(7) However, in our case it presented as acute intestinal obstruction. The differential diagnosis kept were ileocaecal tuberculosis which is highly prevalent in this part of world and colonic tumor.

They may also present as pseudomyxoma peritonei if cystadencarcinoma gets ruptured and deposits epithelial elements and mucin in peritoneal cavity.

Ultrasonography is a valuable tool for diagnosing of MA which shows hypoechoic lesion with an irregular inner wall caused by mucinous debris and varying degrees of epithelial hyperplasia. It is also helpful for diagnosing ascites due to pseudomyxoma peritonei.(8) Recently, CT has been shown to be effective in recognizing the anatomy. It shows a near water density mass in right iliac fossa with focal areas of calcification in the cyst wall.(9) 
MA is treated with appendicectomy. Dhage-Ivatury and Sugarbaker studied the importance for evaluating appendiceal lymph nodes and appendiceal stump. They concluded that if lymph nodes are positive, right hemicolectomy should be performed. However, during resection it should be borne in mind that appendix specimen be removed without rupture so as to prevent any spillage of mucin in peritoneal cavity and hence a few authors recommend conversion to open surgery if mucocele is found at laparoscopic surgery. ${ }^{(10)}$

MA is an uncommon cause of intestinal obstruction. In our case, cystadenoma variety of MA presented with intestinal obstruction. Prior history of pulmonary koch's in patient with an earlier attack of subacute intestinal obstruction led us to keep the possibility of ileocaecal koch's as the $1^{\text {st }}$ diagnosis. During any surgical intervention on MA it should be borne in mind to keep the appendix intact so as to prevent pseudomyxoma peritonei which is a fatal complication.

\section{ABBREVIATIONS: MA- MUCOCELE OF APPENDIX.}

\section{REFERENCES:}

1. STANG A, BRAUMANN D, TEICHMANN W. Mucocele of the appendix. Incidental sonographic discovery and laparoscopic resection. Dtsch Med Wochenschr 2004; 129: 2295-2298.

2. SOWEID AM, CLARKSTON WK, ANDRUS CH, JANNEY CG. Diagnosis and management of appendiceal mucoceles. Dig Dis 1998; 16: 183-186.

3. Mourad FH, Hussein M, Bahlawan M, Haddad M, Tawil A. Intestinal obstruction secondary to appendiceal mucocele. Dig Dis Sci. 1999; 44(8): 1594-9.

4. Ruiz-Tovar J, Teruel DG, Castiñeiras VM, Dehesa AS, Quindós PL, Molina EM. Mucocele of the appendix. World J Surg. 2007; 31(3): 542-8.

5. Chetty R, Daniel WJ. Mucinous cystadenoma of the appendix: an unusual cause of recurrent intussusceptions in an adult. Aust N Z J Surg 1992; 62: 670-1.

6. Abu Zidan FM, al-Hilaly MA, al-Atrabi N. Torsion of a mucocele of the appendix in a pregnant woman. Acta Obstet Gynecol Scand 1992; 71: 140-2.

7. Baskin LS, Stoller ML. Unusual appendiceal pathology presenting as urologic disease. Urology 1991; 38: 432-6.

8. Li YP, Morin ME, Tan A. Litrasound findings in mucocele of the appendix. JCU 1981; 9: 406-408.

9. Mayes GB, Chuang VP, Fisher RG. Case reports: CT of pseudomyxoma peritonei. AJR 1981: 136: 807-808.

10. DHAGE-IVATURY S, SUGARBAKER PH. Update on the surgical approach to of the appendix. J Am Coll Surg 2006; 202: 680-684. 


\section{CASE REPORT}

\section{AUTHORS:}

1. Sourabh Mukharjee

2. Harshit Agarwal

3. Chikila Kanak Durga

4. Anil Kaler

5. Rachan Kathpaul

\section{PARTICULARS OF CONTRIBUTORS:}

1. Senior Resident, Department of General Surgery, PGIMER \& Dr. RML Hospital, New Delhi.

2. Post Graduate, Department of General Surgery, PGIMER \& Dr. RML Hospital, New Delhi.

3. Professor \& HOD, Department of General Surgery, PGIMER \& Dr. RML Hospital, New Delhi.

FINANCIAL OR OTHER COMPETING INTERESTS: None
4. Post Graduate, Department of General Surgery, PGIMER \& Dr. RML Hospital, New Delhi.

5. Post Graduate, Department of General Surgery, PGIMER \& Dr. RML Hospital, New Delhi

\section{NAME ADDRESS EMAIL ID OF THE CORRESPONDING AUTHOR:}

Dr. Harshit Agarwal,

Room No. 123,

Doctors Hostel, Dr. RML Hospital,

New Delhi-110001.

E-mail: drharshitagarwal@outlook.com

Date of Submission: 20/07/2015.

Date of Peer Review: 21/07/2015.

Date of Acceptance: 04/08/2015.

Date of Publishing: 10/08/2015. 